Original Research Article

\title{
Effect of silybin in 1-methyl-4-phenyl-1,2,3,6 tetrahydropyridine (MPTP) induced parkinsonism in mice
}

\author{
Shajil Anand Justin ${ }^{1}$, Senthil Gobalakrishnan ${ }^{2 *}$, Sylvia Santhakumari Asirvatham ${ }^{3}$
}

${ }^{1}$ Department of Pharmacology, Dr. Somervell memorial C.S.I Medical College and Hospital, Karakonam, Kerala, India ${ }^{2}$ Department of Pharmacology, SMVMCH, Puducherrry, India ${ }^{3}$ Department of Pharmacology, RMMCH, Chidambaram,

Tamilnadu, India

Received: 26 July 2017

Accepted: 23 August 2017

*Correspondence to:

Dr. Senthil Gobalakrishnan,

Email: drsenthilgk@gmail.com

Copyright: (C) the author(s), publisher and licensee Medip Academy. This is an openaccess article distributed under the terms of the Creative Commons Attribution NonCommercial License, which permits unrestricted noncommercial use, distribution, and reproduction in any medium, provided the original work is properly cited.

\begin{abstract}
Background: Parkinson disease (PD) is a major neurological disorder known since ancient times. Though drugs are available for therapy, still effective drug targeting the etiopathogenesis is always going on.

Methods: After obtaining permission from animal ethics committee, the mice were divided into four groups of eight each (normal control, experimental control with normal diet only, silybin $300 \mathrm{mg} / \mathrm{kg}$, silybin $600 \mathrm{mg} / \mathrm{kg}$ ). At the end of 55 days the mice were subjected to overnight fasting followed by plasma and liver biochemical analysis.

Results: The mice treated with 1-methyl-4-phenyl-1,2,3,6 tetrahydropyridine (MPTP) developed motor dysfunction and behavioural changes similar to PD, which was tested with rotarod test, photoactometer test and hang test which revealed the impaired performance, hypo-locomotion and impaired neuromuscular strength respectively. Treatment with silybin reversed the motor dysfunction significantly $(\mathrm{p} \leq 0.001)$ in a dose dependent manner. Biochemical analysis measured the oxidant (TBARS, SOD, CAT) and antioxidants (GPx and GSH) which revealed the oxidant activity of MPTP and antioxidant activity of silybin. Histopathological evaluation showed the cytoprotective effect of silybin. Conclusions: Silybin by its antioxidant property has a neuroprotective activity both in motor activity and behaviourally in the MPTP induced Parkinson disease in mice. Hence present study offers a conclusive evidence that silybin is a neuroprotective. Diet supplemented with silybin can protect against neurodegenerative disorders and prevent the progression of neurodegeneration.
\end{abstract}

Keywords: Antioxidant, Neuroprotective, Silybin

\section{INTRODUCTION}

Neurological disorders cause significant morbidity, mortality, disability and socio economic losses. Nearly 33 million Indians have neurological disorders and they occur twice as often in rural areas. ${ }^{1}$ Parkinson's disease (PD) is the second most common form of a group of progressive neurodegenerative disorders that affects $1 \%$ of population over 65 years of age. ${ }^{2} \mathrm{PD}$, known since ancient times, was first cogently described by James Parkinson in 1817. Tremor, rigidity, bradykinesia and postural instability are the cardinal features of Parkinsonism. The patient has a relatively immobile face with widened palpebral fissures, infrequent blinking, and fixity of facial expression. ${ }^{3}$ The most typical pathological hallmark of PD is degeneration of dopaminergic neurons in the nigrostriatal pathway. ${ }^{1}$ The cognitive and some neurobehavioral symptoms have been attributed to degeneration of the dopaminergic mesocortical and mesolimbic pathways, and the associated autonomic dysfunction may be partly caused by dopamine depletion in the hypothalamus. ${ }^{4}$ Besides dopamine deficiency, impairment of other neurotransmitters may be responsible for some of the associated findings. For example, degeneration of the noradrenergic locus coeruleus may contribute to the "freezing" phenomenon and to depression. ${ }^{5}$ Degeneration of the cholinergic nucleus basalis probably relates to the dementia that 
eventually affects about a third of all PD patients. At least an $80 \%$ loss of dopaminergic neurons must appear before clinical symptoms become evident. ${ }^{6}$ This loss takes place over 5-20 years. Hence neuronal degeneration begins long before symptoms appear. Although several hypothesis are currently being investigated, the cause of PD is still unknown. Sporadic and idiopathic PD account for $75 \%$ of all cases of parkinsonism. ${ }^{7}$

Research has concentrated on genetics, exogenous toxins and endogenous toxins from cellular oxidative reactions. The "environmental" hypothesis of PD is primarily based on observation that meperidine analog 1-methyl-4-phenyl1,2,3,6 tetrahydropyridine (MPTP), originally used by heroin addicts, causes parkinsonism in humans and animals. ${ }^{8}$ As a result it has been postulated that some environmental MPTP like toxin might be responsible for human PD. Because ageing is associated with a loss of catecholamine containing neurons and an increase in monoamine oxidase (type A and B) activity, an endogenous toxin hypothesis has emerged. ${ }^{9}$

Based on twin studies, onset of PD before age 50 has a higher likelihood of a genetic cause. ${ }^{10}$ Mutations of genes like $\alpha$ synuclein, parkin, LRRK2, DJ-1 and VCH-L1 have been identified, in causing young onset parkinsonism. Barucha et al, specifically studied the prevalence of PD in the parsi community in India and found rates varying between $6-328 / 10^{5}$ population. ${ }^{12}$ Studies from non parsi communities show prevalence rate varying from $14-41 / 10^{5}$ population. Whether genetic factors in the closed community or some environmental toxin present in the area is causing this high prevalence is unknown.

Epidemiological studies, post mortem biochemical observation, studies of toxin models of PD and genetic studies reveal that oxidative stress and mitochondrial dysfunction are the culprits in the pathogenesis of PD. Hence it would be desirable to identify a treatment that provide neuroprotection against oxidative stress associated with PD. Present medications, surgery and multidisciplinary management can provide only relief from symptoms and neither cure the disease nor offer neuroprotection. Moreover drug therapy is associated with adverse effects like on/off phenomenon, psychosis, diskinesias, postural hypotension and very rarely adverse effects like malignant neuroleptic syndrome.

In recent years, antioxidants have been subjected to epidemiological studies that have related their consumption to a reduction in the incidence of oxidative damage related diseases like ageing, cardiovascular diseases, diabetes, inflammation and neurodegenerative diseases. ${ }^{11}$ Coenzyme $\mathrm{Q}_{10}$, an antioxidant has been shown to have neuroprotection against multiple toxic agents in vitro and animal models of PD. ${ }^{12}$ Many antioxidants such as cytosine, bromcriptine, melatonin, deprenyl and edaraone, have been reported to protect against MPTP induced neurotoxicity in mice. ${ }^{13-17}$
Silymarin, a flavonolignan obtained from an edible plant 'milk thistle' has been used for more than 2000 years as a herbal medicine for the treatment of liver related disorders. ${ }^{18}$ This product generates an annual business of 180 million US dollars in Germany alone. Silymarin consists of four flavonolignan isomers, namely silybin, isosilybin, silydianin and silychristin. ${ }^{18}$ Among them, silybin (50-60\% of silymarin) is the most active substance and is largely responsible for the claimed benefit of silymarin. Its mechanism of action includes inhibition of hepatotoxin binding to receptor site on the hepatocyte, reduction in glutathione oxidation, antioxidant activity, stimulation of ribosomal RNA polymerase and subsequent protein synthesis, leading to enhanced hepatocyte regeneration. ${ }^{19}$ Various animal studies have reported that silybin's antioxidant effect helps protect skin against photocarcinogenesis, renal tissue against cisplatin induced nephrotoxicity and also found to reduce serum cholesterol and triglyceride level. Wang et al, demonstrated that silymarin could effectively protect dopaminergic neurons against lipopolysaccharide (LPS) induced neurotoxicity. ${ }^{20}$ However studies validating the neuroprotective effect of silybin in neurodegenerative disorders like Alzheimer's disease and PD are lacking.

Hence, present study was done to explore the neuroprotective effect of silybin in animal model of PD.

\section{METHODS}

\section{Study centre}

The study was undertaken at Central Animal House, Rajah Muthiah Medical College and Hospital, Annamalai University, Annamalai Nagar, Tamil Nadu, India. All studies were conducted in accordance with the National Institute of Health "Guide for the care and use of Laboratory Animals" (NIH, 1985).

Duration of study was about 55 days.

\section{Materials}

\section{Chemicals and reagents}

- 1-Methyl -4- Phenyl: 1, 2, 3, 6 tetrahydropyridine hydrochloride (MPTP $\mathrm{Hcl}$ ) was purchased from M/S Sigma Chemicals Co., St. Louis, U.S.A.

- Silybin (siliphos) was purchased from Swanson Health Products (Indena S.p.A., Italy) U.S.A.

Each 300mg capsule of siliphos contained 89-109mg of Silybin. The other ingredients were microcrystalline cellulose (plant fiber), gelatin, magnesium stearate and silica.

- $\quad$ Biochemical and enzymatic kits for measuring lipid peroxidase and antioxidants enzymes were obtained from Sigma Aldrich chemicals.

The most widely studied experimental system of PD is the Murine MPTP model. ${ }^{21}$ Male Albino mice of 25-30gms 
were used for this study. Animals were housed in polypropylene cages $(28 \mathrm{~cm} \times 22 \mathrm{~cm} \times 14 \mathrm{~cm})$ bedded with husk in groups of eight under controlled environmental conditions (Temp- $23 \pm 2{ }^{\circ} \mathrm{C}$, Humidity $65-70 \%$ and $12 \mathrm{hrs}$ light/dark cycles).

\section{Experimental induction of $P D$}

MPTP powder was dissolved in saline $(1 \mathrm{mg} / 1 \mathrm{ml})$ to make a solution. Initially a pilot study was done with different doses of MPTP administered intraperitoneally (I.P) to determine which of them might be useful to establish severe striatal lesion. A dose of $25 \mathrm{mg} / \mathrm{kg}$ administered I.P. twice at $16 \mathrm{hrs}$ apart, had a low risk of lethality and led to extensive damage in the corpus striatum and substantia nigra. $^{22}$

The mice were divided into four groups of eight each. The animals were housed in the animal house for 55 days.

- $\quad$ Group-I $(n=8)$ : Normal control. Treated with normal diet only.

- Group-II (n=8): Experimental control. Treated with normal diet only.

- Group-III ( $n=8)$ : Silybin $300 \mathrm{mg} / \mathrm{kg}$ orally once daily.

- $\quad$ Group $-I V(n=8)$ : Silybin $600 \mathrm{mg} / \mathrm{kg}$ orally once daily.

Silybin was mixed with normal saline and administered through oral intragastric tube to groups III and IV for 45 days prior to induction of PD. At the end of 45 days, MPTP $(25 \mathrm{mg} / \mathrm{kg})$ was administered I.P twice at 16 hours apart, to groups II, III, and IV to induce PD. After induction of PD, groups III and IV were treated with silybin for 7 more days while Groups I and II received normal diet. On the $7^{\text {th }}$ day after the last MPTP dosing, behavioural studies were done in all the groups. ${ }^{14}$ The animals in all the groups were sacrificed by cervical dislocation under intramuscular (IM) ketamine $(30 \mathrm{mg} / \mathrm{kg})$ and the brains of mice were quickly removed. The striatum and midbrain were dissected and processed for histopathological and biochemical analyses.

\section{Statistical analysis}

Values of Behavioral study and Biochemical analysis were expressed as means \pm SD for eight mice in each group. The data were analyzed by Tukey's range test. Statistical analyses were performed using a software package SYSTAT 12 . Value of $\mathrm{p} \leq 0.001$ was used as the criterion for statistical significance.

\section{RESULTS}

\section{Effect of Silybin on MPTP induced motor impairment and behavioral deficits}

From Table 1, it was observed that MPTP was able to induce significant impairment in locomotion, motor coordination, motor balance and neuromuscular strength when compared with saline treated mice. The hanging period of MPTP treated mice was only $50 \%$ of the control group. Results showed that silybin at both doses (300 and $600 \mathrm{mg} / \mathrm{kg}$ ) enhanced the neuromuscular strength in MPTP mice markedly $(\mathrm{p} \leq 0.001)$.

Table 1: Effect of silybin on MPTP induced behavioral deficits in mice.

\begin{tabular}{|lllll|}
\hline Groups & $\begin{array}{l}\text { Rotarod test } \\
\text { (Latency in seconds) }\end{array}$ & $\begin{array}{l}\text { Hang test } \\
\text { (Hang time in } \\
\text { seconds) }\end{array}$ & $\begin{array}{l}\text { Photo-actometer } \\
\text { (No. of counts/ } \\
\text { 60min) }\end{array}$ & $\begin{array}{l}\text { Fore paw stride } \\
\text { length on left } \\
\text { side (in cm) }\end{array}$ \\
\hline Control & $600.00 \pm 0.00^{\mathrm{a}}$ & $30.00 \pm 0.00^{\mathrm{a}}$ & $4156.83 \pm 500.78^{\mathrm{a}}$ & $7.10 \pm 0.00^{\mathrm{a}}$ \\
\hline MPTP & $334.56 \pm 105.86^{\mathrm{b}}$ & $14.87 \pm 0.77^{\mathrm{b}}$ & $2604.750 \pm 336.99^{\mathrm{b}}$ & $5.85 \pm 0.00^{\mathrm{b}}$ \\
\hline $300 \mathrm{mg} / \mathrm{kg} \mathrm{Silybin} \mathrm{+} \mathrm{MPTP}$ & $465.06 \pm 126.30^{\mathrm{c}}$ & $20.30 \pm 0.62^{\mathrm{c}}$ & $3335.50 \pm 442.76^{\mathrm{c}}$ & $6.45 \pm 0.03^{\mathrm{c}}$ \\
\hline $600 \mathrm{mg} / \mathrm{kg} \mathrm{Silybin} \mathrm{+} \mathrm{MPTP}$ & $578.12 \pm 61.87^{\mathrm{d}}$ & $23.51 \pm 1.76^{\mathrm{d}}$ & $3859.75 \pm 577.28^{\mathrm{d}}$ & $6.83 \pm 0.02^{\mathrm{d}}$ \\
\hline
\end{tabular}

Values are expressed as means \pm S.D. for eight mice in each group.

Values not sharing a common superscript differ significantly at $\mathrm{p} \leq 0.001$ (Tukey's range test)

Table 2: Effect of silybin on lipid peroxides and antioxidants in corpus striatum and Substantia nigra of mice treated with MPTP.

\begin{tabular}{|c|c|c|c|c|c|}
\hline Groups & $\begin{array}{l}\text { TBARS } \\
\text { (mmole/100g } \\
\text { wet tissue) }\end{array}$ & $\begin{array}{l}\text { GSH } \\
\text { ( } \mathrm{g} / \mathrm{mg} \\
\text { protein) }\end{array}$ & $\begin{array}{l}\text { GPx } \\
\left(\mu \mathrm{mol}{ }^{\circledR} / \mathrm{mg}\right. \\
\text { protein) }\end{array}$ & $\begin{array}{l}\text { SOD } \\
\text { (unit*/mg } \\
\text { protein) }\end{array}$ & $\begin{array}{l}\text { CAT } \\
\text { ( } \mu \text { mole } / \mathrm{mg} \\
\text { protein) }\end{array}$ \\
\hline Control & $12.66 \pm 0.41^{\mathrm{a}}$ & $13.56 \pm 0.44^{\mathrm{a}}$ & $7.09 \pm 0.14^{\mathrm{a}}$ & $3.37 \pm 0.03^{\mathrm{a}}$ & $0.12 \pm 0.05^{\mathrm{a}}$ \\
\hline MPTP & $20.73 \pm 1.35^{\mathrm{b}}$ & $7.83 \pm 0.28^{b}$ & $4.01 \pm 0.19^{\mathrm{b}}$ & $5.81 \pm 0.10^{\mathrm{b}}$ & $0.73 \pm 0.05^{\mathrm{b}}$ \\
\hline 300mg/kg Silybin + MPTP & $16.53 \pm 0.68^{c}$ & $9.29 \pm 0.48^{c}$ & $5.54 \pm 0.34^{\mathrm{c}}$ & $4.91 \pm 0.07^{c}$ & $0.46 \pm 0.07^{\mathrm{c}}$ \\
\hline 600mg/kg Silybin + MPTP & $12.66 \pm 0.73^{\mathrm{d}}$ & $12.90 \pm 0.68^{\mathrm{d}}$ & $7.05 \pm 0.14^{\mathrm{d}}$ & $3.75 \pm 0.44^{\mathrm{d}}$ & $0.19 \pm 0.01^{\mathrm{d}}$ \\
\hline
\end{tabular}

Values are expressed as means \pm SD for eight mice in each group.

Values not sharing a common superscript differ significantly at $p \leq 0.001$ (Tukey's range test).

$\stackrel{@}{@}=\mu \mathrm{mol}$ of GSH utilized/minute

*=Enzyme concentration required to inhibit the chromogen produced by $50 \%$ in one minute under standard condition was taken as one unit, ${ }^{\circ}=\mu \mathrm{mol}$ of hydrogen peroxide decomposed/minute. 
Results of rotarod test showed that MPTP reduced the retention time significantly when compared with control group. Pretreatment with silybin improved the rotarod performance in a dose dependant manner. silybin at $(600 \mathrm{mg} / \mathrm{kg}$, I.P.) markedly improved rotarod performance $(\mathrm{p} \leq 0.001)$.

The photoactometer test showed a significant reduction in spontaneous motor activity of MPTP treated mice. Pretreatment with silybin at both doses (300 and $600 \mathrm{mg} / \mathrm{kg}$ ) significantly attenuated MPTP induced hypolocomotion $(\mathrm{p} \leq 0.001)$.

In Table 2 the tukey's range test indicates significant reduction in forepaw stride length in MPTP treated mice when compared with control group. Pre treatment with $600 \mathrm{mg} / \mathrm{kg}$ of silybin showed marked improvement, almost equal to the forepaw stride length of control mice ( $p$ $\leq 0.001)$.

\section{Biochemical analysis}

The level of TBARS presented in Table 2 was significantly elevated in the mid brain and corpus striatum of MPTP treated mice $(\mathrm{p} \leq 0.001)$. Compared to control group, silybin at $600 \mathrm{mg} / \mathrm{kg}$, significantly $(\mathrm{p} \leq 0.001)$ decreased TBARS level than at $300 \mathrm{mg} / \mathrm{kg}$.

Striatal antioxidant levels of GPx and GSH were significantly reduced in MPTP treated group when compared with control ( $\mathrm{p} \leq 0.001)$. Higher dose of silybin $(600 \mathrm{mg} / \mathrm{kg})$ restored GPx and GSH activities to near normal.

SOD and CAT activities of MPTP treated mice were significantly increased when compared with control ( $p$ $\leq 0.001)$. Though the SOD and CAT were also increased in silybin treated mice significantly $(\mathrm{p} \leq 0.001)$ at both doses, their levels were significantly less when compared to MPTP treated group $(\mathrm{p} \leq 0.001)$.

\section{Histopathological evaluation}

Mice treated with MPTP showed marked apoptosis of neuronal cells with pyknotic nuclei and cytoplasmic eosinophilia. There was a marked reactive gliosis with increase in nuclear size, vesicular nuclei, coarse chromatin and moderate cytoplasm. A moderate to severe microglial activation was also noted. The MPTP treated mice brain also showed a lesser neuronal density per high power field than the mice brain treated with silybin.

Mice treated with silybin $(600 \mathrm{mg} / \mathrm{kg})$ showed the highest density of neurons, least amount of neuronal damage with decreased apoptosis, lesser gliosis, lesser microglial activation and lesser rosenthal fibres. Mice treated with silybin $300 \mathrm{mg} / \mathrm{kg}$ showed an intermediate picture.

All the Figures shows photo micrographs of brain tissue of mice.

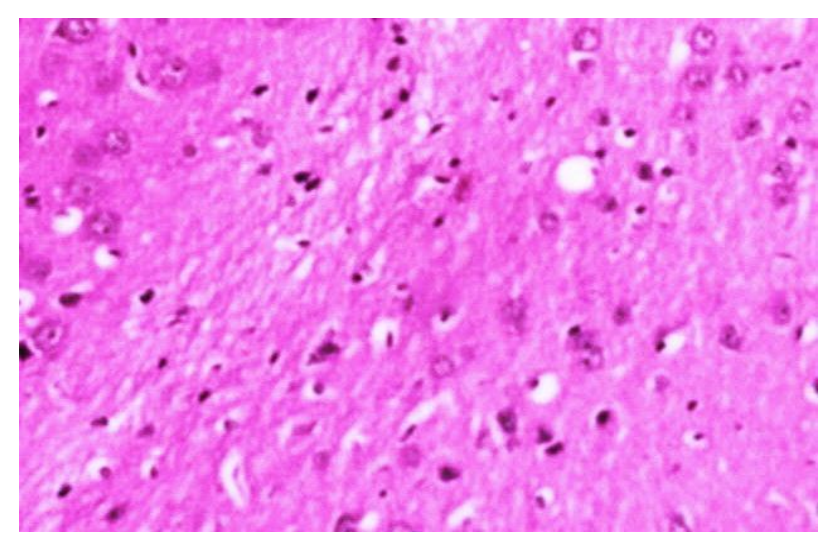

Figure 1: Corpus striatum of control group showing normal neuronal cell structure.

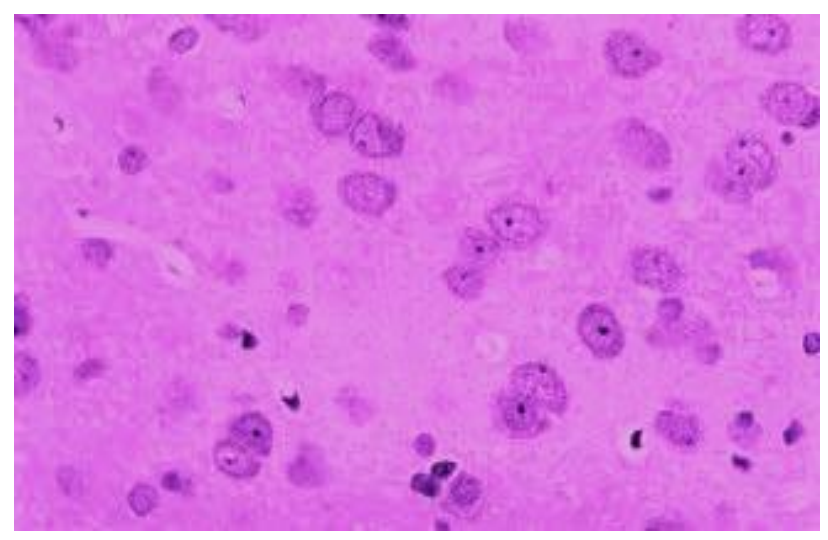

Figure 2: Substantia nigra of control group showing normal neuronal cell structure.

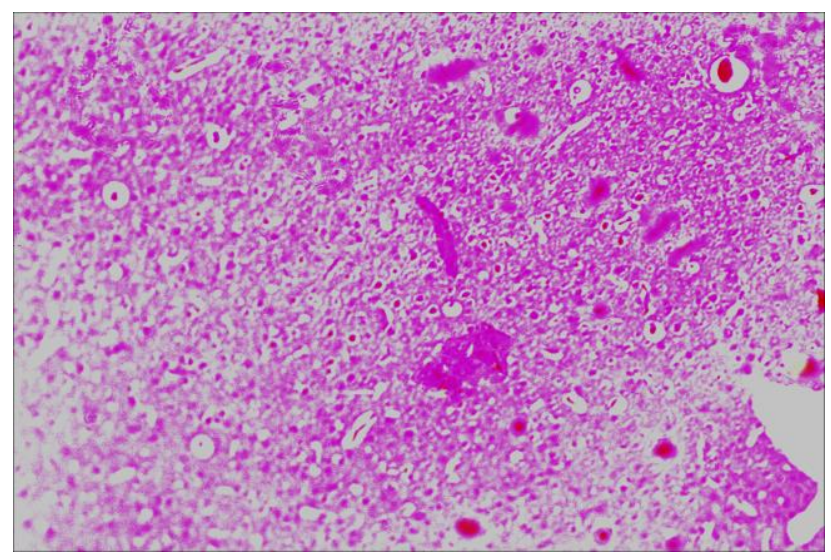

Figure 3: Corpus striatum of MPTP treated mice showing marked reactive gliosis with increase in nuclear size, vesicular nuclei, coarse chromatin, extensive areas of rosenthal fibres, moderate to severe microglial activation and decreased neuronal density.

\section{DISCUSSION}

Parkinson's disease is a neurodegenerative disorder mainly characterized by motor deficits resulted by the decrease of dopaminergic neurons in the Substantia nigra pars compacta. 


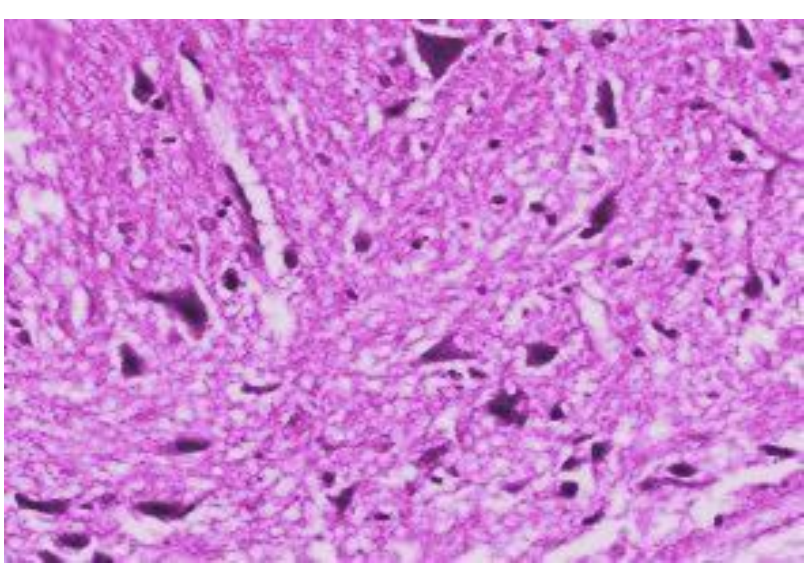

Figure 4: Substantia nigra of MPTP treated mice showing marked apoptosis of neuronal cells with pyknotic nuclei, cytoplasmic eosinophilia, extensive areas of rosenthal fibres, moderate to severe microglial activation and decreased neuronal density.

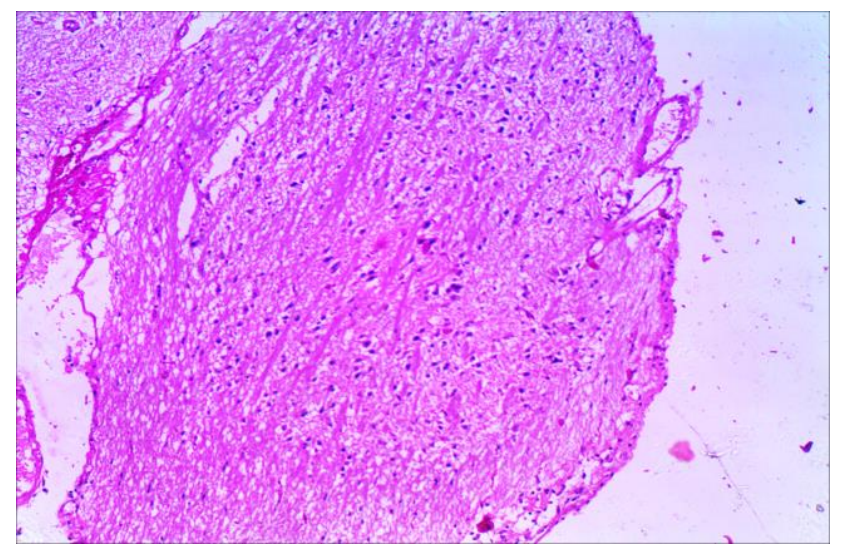

Figure 5: Corpus striatum of $300 \mathrm{mg} / \mathrm{kg}$ Silybin + MPTP treated mice showing moderate reactive gliosis, moderate apoptosis, moderate areas of rosenthal fibres, moderate microglial activation and moderate neuronal density.

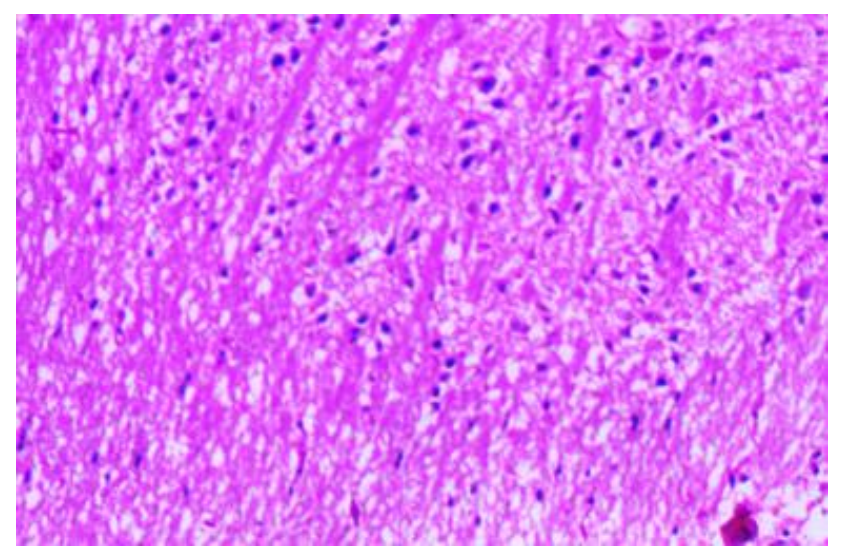

Figure 6: Substantia nigra of 300mg/kg Silybin + MPTP treated mice showing moderate apoptosis of neuronal cells with pyknotic nuclei, cytoplasmic eosinophilia, many areas of rosenthal fibres, moderate microglial activation and moderate neuronal density.

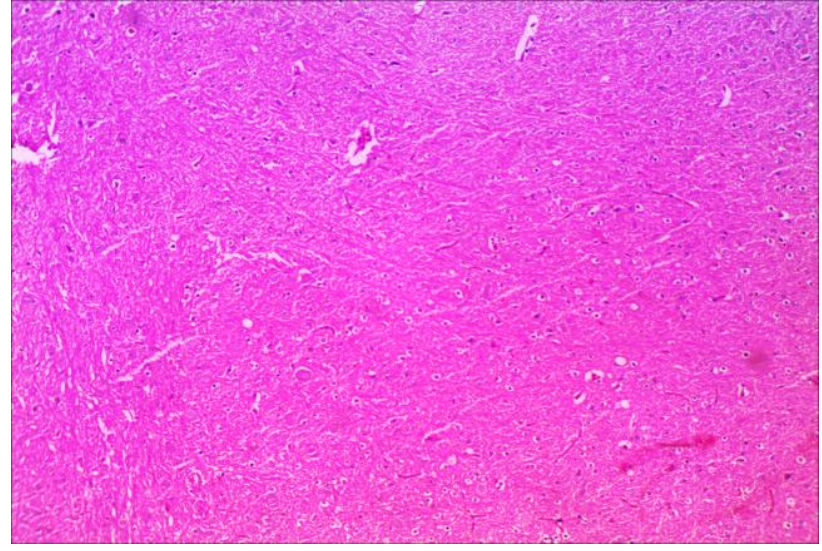

Figure 7: Corpus striatum of $600 \mathrm{mg} / \mathrm{kg}$ Silybin + MPTP treated mice showing mild reactive gliosis, mild apoptosis, few areas of rosenthal fibres, mild microglial activation and more neuronal density.

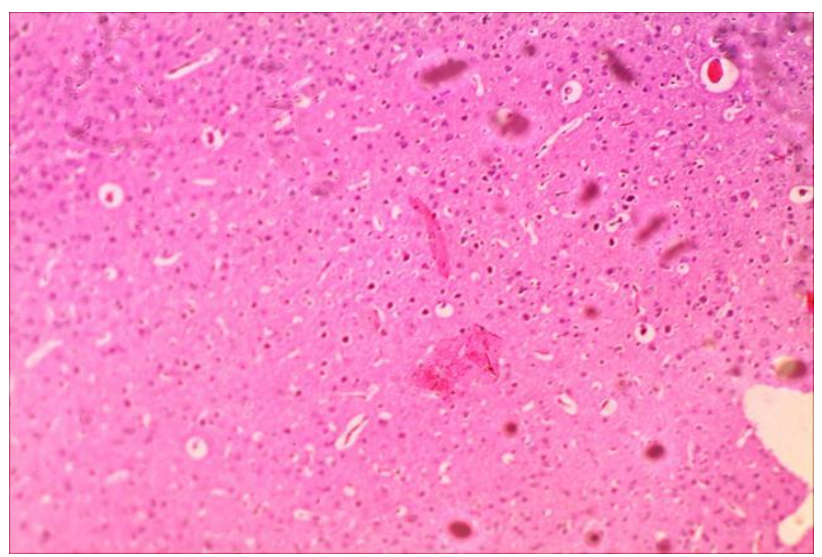

Figure 8: Substantia nigra of $600 \mathrm{mg} / \mathrm{kg}$ Silybin + MPTP treated mice showing showing few neurons with pyknotic nuclei, mild apoptosis, few rosenthal fibres, mild microglial activation and more neuronal density.

The etiology of PD is complex, and although the mutation of several genes results in rare forms of PD, the vast majority of PD is the sporadic form. Free radical stress contributes to pathogenesis of this idiopathic disorder. ${ }^{23}$ An increasing number of human epidemiological studies and animal studies show that nutritional antioxidants are capable of preventing oxidative damage and render significant neuroprotection. ${ }^{24}$

The murine MPTP model constitutes the best characterized toxin paradigm for PD, faithfully replicating most of its clinical and pathological hallmarks. ${ }^{25}$ Various studies had been done to assess the time course of MPTP induced cell death in mice and have proved that greatest loss of dopaminergic neurons was observed at 7 days. ${ }^{26}$ Hence in the present study also swiss male albino mice were used and they were subjected to behavioral, biochemical and histopathological analysis at 7 days after last MPTP dosing. 
MPTP is metabolized to its active toxin, $\mathrm{MPP}^{+}$, in the brain by the action of MAO. This enzymatic conversion of MPTP to $\mathrm{MPP}^{+}$is shown to involve generation of free radicals. The biochemical analysis of corpus striatum and substantia nigra of MPTP treated mice in the present study revealed increased lipid peroxidation, significant decrease in GSH and GPx levels. Pretreatment with silybin significantly reduced the TBARS level in a dose dependant manner. The depletion of GSH and GPx following MPTP administration is indicative of utilization of these antioxidants for effectively removing free radicals formed in brain. GSH and GPx protect cells from oxidative stress and the depletion of GSH is the earliest biochemical change in the brains of PD patients. ${ }^{27}$ Thus, a decreased GSH and GPx levels serves as an indicator of oxidative stress. Interestingly pretreatment with silybin made a notable improvement in the levels of GSH and GPx in the PD mouse model. Silybin by preventing the lipid peroxidation induced by MPTP, had restored the activities of GSH and GPx. Silymarin a complex mixture of four flavonolignan isomers, namely silybin, isosilybin, silydianin and silychristin (with silybin being the most active) has been widely used from ancient times to treat human liver disorders. ${ }^{18}$ The antioxidant and free radical scavenging properties attribute to one of the several mechanisms for silymarin's hepatoprotective effect. Various animal studies have also demonstrated that silybin was shown to have anticancer and hypocholesterolaemic activities through its antioxidant defense mechanism. ${ }^{28,29}$

In our study, administration of MPTP showed increased activities of SOD and CAT which were correlated with previous experiments (Muralikrishnan and Mohanakumar). ${ }^{12}$ This result suggested a compensatory response to oxidative stress due to an increase in endogenous $\mathrm{H}_{2} \mathrm{O}_{2}$ production. Thus the decreased level of SOD and CAT in silybin pretreated groups predicts that silybin contain free radical scavenging activity, which could exert a beneficial action against the pathological alteration caused by the presence of $\mathrm{O}_{2}^{-}$and $\mathrm{OH}^{-}$. The major observation of this study was the recovery of free radical induced damage in brain cells by silybin.

In our study the MPTP treated mice showed motor dysfunction and behavioural changes similar to PD. Various animal studies have reported that mice intoxicated with MPTP developed symptoms like hypo-locomotion, impaired motor initiation, impaired balance, impaired coordination and reduced grip strength. ${ }^{30}$ In the present study the MPTP treated mice when subjected to rotarod test, showed impaired performance, revealing a significant loss of muscle coordination and balance. Photoactometer test showed hypo-locomotion and hang test revealed impaired neuromuscular strength in MPTP treated mice. The forelimb stride length measurement test, used to test PD gait performance was also significantly altered by MPTP treatment.

Motor impairment is observed only after severe dopamine depletion (70-80\%) in the striatum in PD patients. ${ }^{6}$ Silybin reversed MPTP induced motor dysfunction significantly in a dose dependent manner. This proved preservation of dopaminergic neurons by silybin and its neuroprotection against MPTP induced toxicity. Gait disturbances are characteristic of PD. Gait reflects several variables, including balance, proprioception and coordination. Several studies in mouse models of PD have described "gait" by estimating stride length and stance width. ${ }^{31}$ Fernagut et al, reported that stride length is a reliable index of motor disorders due to basal ganglia dysfunction in mice. ${ }^{32}$ In the present study silybin at both doses (300 and $600 \mathrm{mg} / \mathrm{kg}$ ) reversed the reduction in stride length by MPTP. Thus biochemical analysis and motor function tests clearly proved that silybin protects against MPTP induced neurotoxicity by its antioxidant defensive mechanism.

The neuroprotective effect of silybin was further confirmed by histopathological study of nigrostrial neurons. MPTP treated mice showed extensive necrosis of striatal neurons, cellular oedema, severe microglial activation, intense gliosis, apoptosis of neuronal cells with pyknotic nucleus and extensive areas of rosenthal fibres. Previous studies have also showed necrosis of cells, cellular oedema, local microglial activation, rosenthal fibres and extensive gliosis in MPTP treated mice. ${ }^{33,17}$ Local microglial activation within the nigrostriatum is a secondary reaction to dopaminergic neuro degeneration. Microglial activation can also exacerbate ROS production. Mice treated with silybin $(600 \mathrm{mg} / \mathrm{kg})$ showed the highest density of neurons and least amount of neuronal damage.

Many antioxidants (radical scavengers) such as bromocriptine, cytosine, melatonin, edaravone have been reported to protect against MPTP induced neurotoxicity. ${ }^{13,14,17,34}$

The findings in the present study also showed that silybin by its antioxidant mechanism plays a cytoprotective role in substantia nigra and corpus striatum in MPTP induced PD in mice.

\section{CONCLUSION}

Hence present study offers a conclusive evidence that silybin is a neuroprotective. Diet supplemented with silybin can protect against neurodegenerative disorders and prevent the progression of neurodegeneration. Further studies on silybin are needed to evaluate its action on nitric oxide production inhibition, iNOS gene activation, proinflammatory cytokines like tumor necrosis factor $\alpha$ (TNF- $\alpha$ ), proapoptotic proteins, mitochondrial ATP synthesis and excitotoxic events that contribute to neurodegeneration.

\section{ACKNOWLEDGEMENTS}

Authors would like to thank the Department of Pharmacology of Raja Muthiah medical college (RMMCH), Chidambaram for guiding and helping to carry 
out the study and Department of Biochemistry and Pathology of RMMCH in carrying out the investigations.

Funding: No funding sources

Conflict of interest: None declared

Ethical approval: The study was approved by the Institutional Animal Ethics Committee of Rajah Muthiah Medical College and Hospital, [160/1999/(CPCSIA)] and Annamalai Nagar, Tamil Nadu, India (Proposal No.791, dated 20.04.2011)

\section{REFERENCES}

1. Lang AE. Parkinsonism. In Goldman's Cecil Medicine. Eds Lee Goldman, Dennis Ausiello, 23rded. Saunders, Elsevier. New Delhi. 2007;433(2):2326-33.

2. Devi GM, Gururaj G, Satishchandra P. Neuroepidemiology in developing countries. Manual for descriptive studies. National Institute of Mental Health and Neurosciences (NIMHANS), Bangalore. Publication No.33;1994.

3. Jankovic J. Parkinson's disease: clinical features and diagnosis. J. Neurol. Neurosurg. Psychiatry. 2008;79(4):368-76.

4. Schott BH, Niehaus L, Wittmann BC, Schütze H, Seidenbecher CI, Heinze HJ, et al. Ageing and earlystage Parkinson's disease affect separable neural mechanisms of mesolimbic reward processing. Brain. 2007 Jul 11;130(9):2412-24.

5. Tom T, Cummings JL. Depression in Parkinson's disease. Pharmacological characteristics and treatment. Drugs Ageing. 1998;12(1):55-74.

6. Chen JJ, Nelson MV, Swope DM. Parkinson's disease. In Pharmacotherapy. A Pathophyiological Approach. Eds Joseph T. DiPiro, Barbara G. Wells, Cecily V. DiPiro, Terry L. Schwinghammer, $7^{\text {th }}$ Ed. McGrawHill Book Co. Newyork, 2008;61:977-988.

7. Mahlon R, DeLong, Jorge L, Juncos. Parkinson's disease and other extrapyramidal movement disorders. In Harrison's Principles of Internal Medicine. Eds Fauci AS,Braunwald E, Kasper DL, Hauser SL, Longo DL, Jameson JL, Loscalzo J, $17^{\text {th }}$ Ed. McGraw-Hill Book Co. Newyork. 2008;366:2549-59.

8. Langston JW, Ballard P, Irwin I. Chronic Parkinsonism in humans due to a product of meperidine-analog synthesis. Science. 1983;219:97980.

9. Alper G, Girgin FK, Ozgönül M, Menteş G, Ersöz B. MAO inhibitors and oxidant stress in aging brain tissue. European neuropsycho pharmacology. 1999 Mar 1;9(3):247-52.

10. Tanner CM, Ottman R, Goldman SM, Ellenberg J, Chan P, Mayeux R, et al. Parkinson disease in twins: an etiologic study. Jama. 1999 Jan 27;281(4):341-6.

11. Zheng W, Wang SY. Antioxidant activity and phenolic compounds in selected herbs. J. Agric. Food Chem. 2001;49(11):5165-70.

12. Shults CW, Oakes D, Kieburtz K, Beal MF, Haas R, Plumb S, et al. Effects of coenzyme Q10 in early
Parkinson disease: evidence of slowing of the functional decline. Archives of neurology. 2002 Oct 1;59(10):1541-50.

13. Ferger B, Spratt C, Teismann P, Seitz G, Kuschinsky $\mathrm{K}$. Effects of cytisine on hydroxyl radicals in vitro and MPTP-induced dopamine depletion in vivo. European journal of pharmacology. 1998 Nov 6;360(2):155-63.

14. Muralikrishnan D, Mohanakumar KP. Neuroprotection by bromocriptine against 1-Methyl4-phenyl-1,2,3,6-tetrahydropyridine-induced neurotoxicity in mice. FASEB J. 1998;12:905-12.

15. Antolín I, Mayo JC, Sainz RM, del Brío MD, Herrera F, Martín V, et al. Protective effect of melatonin in a chronic experimental model of Parkinson's disease. Brain research. 2002 Jul 12;943(2):163-73.

16. Fuller RW, Hemrick-Luecke SK. Deprenyl protection against striatal dopamine depletion by 1-methyl-4phenyl-1,2,3,6-tetrahydropyridine in mice. Res Comm Sub Abuse. 1984;5:241-6.

17. Kawasaki T, Ishihara K, Ago Y, Baba A, Matsuda T. Edaravone (3-methyl-1-phenyl-2-pyrazolin-5-one), a radical scavenger, prevents 1-methyl-4-phenyl-1, 2, 3, 6-tetrahydropyridine-induced neurotoxicity in the substantia nigra but not the striatum. Journal of Pharmacology and Experimental Therapeutics. 2007 Jul 1;322(1):274-81.

18. Saller R, Meier R, Brignoli R. The use of silymarin in the treatment of liver diseases. Drugs. 2001 Dec $1 ; 61(14): 2035-63$.

19. Dixit N, Baboota S, Kohli K, Ahmad S, Ali J. Silymarin: A review of pharmacological aspects and bioavailability enhancement approaches. Indian journal of pharmacology. 2007 Jul 1;39(4):172.

20. Wang AL, Albert CH, Lau LT, Lee C, Tso MO. Minocycline inhibits LPS-induced retinal microglia activation. Neurochemistry international. $2005 \mathrm{Jul}$ 31;47(1):152-8.

21. Smeyne RJ, Jackson-Lewis V. The MPTP model of Parkinson's disease. Brain Res Mol Brain Res. 2005;134(1):57-66.

22. Hamre K, Tharp R, Poon K, Xiong X, Smeyne RJ. Differential strain susceptibility following 1-methyl4-phenyl-1, 2, 3, 6-tetrahydropyridine (MPTP) administration acts in an autosomal dominant fashion: quantitative analysis in seven strains of Mus musculus. Brain research. 1999 May 15;828(1):91-103.

23. Carter CA, Pogribny M, Davidson A, Jackson CD, McGarrity LJ, Morris SM. Effects of retinoic acid on cell differentiation and reversion toward normal in human endometrial adenocarcinoma (RL95-2) cells. Anticancer research. 1996;16(1):17-24.

24. Zandi PP, Anthony JC, Khachaturian AS, Stone SV, Gustafson D, Tschanz JT, et al. Reduced risk of Alzheimer disease in users of antioxidant vitamin supplements: The Cache County Study. Archives of neurology. 2004 Jan 1;61(1):82-8.

25. Meredith GE, Sonsalla PK, Cheselet. Animal models of Parkinson's disease progression. Acta Neuropathol. 2008;115:385-98. 
26. Jackson-Lewis V, Jakowec M, Burke RE, Przedborski S. Time course and morphology of dopaminergic neuronal death caused by the neurotoxin 1-methyl-4phenyl-1, 2, 3, 6-tetrahydropyridine. Neurodegeneration. 1995 Sep 30;4(3):257-69.

27. Perry TL, Godin DV, Hansen S. Parkinson's disease: a disorder due to nigral glutathione deficiency? Neuroscience Letters. 1982;33:305-10.

28. Singh RP, Dhanalakshmi S, Tyagi AK, Chan DC, Agarwal C, Agarwal R. Dietary feeding of silibinin inhibits advance human prostate carcinoma growth in athymic nude mice and increases plasma insulin-like growth factor-binding protein-3 levels. Cancer research. 2002 Jun 1;62(11):3063-9.

29. He WX, Zhang S, Yang Q. Nutritional compositions of Silybum marianum gaertn seed oil and its hypolipidemic effect in rats. Acta Nutrimenta Sinica. 1996;18:163-7.

30. Tillerson JL, Michael Caudle W, Reverson ME. Detection of behavioural impairments correlated to neuro chemical deficits in mice treated with moderate doses of 1-methyi-4-phenyl-1,2,3,6tetrahydropyridine. Exp Neuro. 2002;178:80-90.

31. Thaut MH, Miltner R, Lange HW, Hurt CP, Hoemberg V. Velocity modulation and rhythmic synchronization of gait in Huntington's disease. Movement Disorders. 1999 Sep 1;14(5):808-19.

32. Fernagut PO, Diguet E, Labattu B, Tison F. A simple method to measure stride length as an index of nigrostriatal dysfunction in mice. Journal of neuroscience methods. 2002 Jan 30;113(2):123-30.

33. Mohanasundari M, Srinivasan MS, Sethupathy S, Sabesan M. Enhanced neuroprotective effect by combination of bromocriptine and Hypericum perforatum extract against MPTP-induced neurotoxicity in mice. J of the Neu Sci. 2006 Nov 15;249(2):140-4.

34. Chen LJ, Gao YQ, Li XJ, Shen DH, Sun FY. Melatonin protects against MPTP/MPP+-induced mitochondrial DNA oxidative damage in vivo and in vitro. Journal of pineal research. 2005 Aug 1;39(1):3442 .

Cite this article as: Justin SA, Senthil G, Sylvia SA. Effect of silybin in 1-methyl-4-phenyl-1,2,3,6 tetrahydropyridine (MPTP) induced parkinsonism in mice. Int J Basic Clin Pharmacol 2017;6:2414-21. 